NBER WORKING PAPER SERIES

\title{
SKIPPING THE BAG: \\ THE INTENDED AND UNINTENDED CONSEQUENCES \\ OF DISPOSABLE BAG REGULATION
}

\author{
Tatiana Homonoff \\ Lee-Sien Kao \\ Javiera Selman \\ Christina Seybolt \\ Working Paper 28499 \\ http://www.nber.org/papers/w28499
NATIONAL BUREAU OF ECONOMIC RESEARCH
1050 Massachusetts Avenue
Cambridge, MA 02138
February 2021

We are grateful to Emma Berndt, Jacob Goldin, Doug Palmer, Travis St. Clair, and Becca Taylor for providing helpful feedback. Betsy Priem, Claire Costelloe, May-May Chen, Juliana Tu, Ilve Bayturk, Tyler He, Grace Martin, Chimdi Obienu, Kaiti Zolton, and Anirudh Duvvuru provided excellent research assistance in collecting data for this project. The City of Chicago provided original funding for the data collection for this work. The views expressed herein are those of the authors and do not necessarily reflect the views of the National Bureau of Economic Research.

NBER working papers are circulated for discussion and comment purposes. They have not been peer-reviewed or been subject to the review by the NBER Board of Directors that accompanies official NBER publications.

(C) 2021 by Tatiana Homonoff, Lee-Sien Kao, Javiera Selman, and Christina Seybolt. All rights reserved. Short sections of text, not to exceed two paragraphs, may be quoted without explicit permission provided that full credit, including $\odot$ notice, is given to the source. 
Skipping the Bag: The Intended and Unintended Consequences of Disposable Bag Regulation Tatiana Homonoff, Lee-Sien Kao, Javiera Selman, and Christina Seybolt

NBER Working Paper No. 28499

February 2021

JEL No. H23,H71,Q53

\begin{abstract}
$\underline{\text { ABSTRACT }}$
Regulation of goods associated with negative environmental externalities may decrease consumption of the targeted product, but may be ineffective at reducing the externality itself if close substitutes are left unregulated. We find evidence that plastic bag bans, the most common disposable bag regulation in the US, led retailers to circumvent the regulation by providing free thicker plastic bags which are not covered by the ban. In contrast, a regulation change that replaced the ban with a small tax on all disposable bags generated large decreases in disposable bag use and overall environmental costs. Our results suggest that narrowly-defined regulations (like plastic bag bans) may be less effective than policies that target a more comprehensive set of products, even in the case when the policy instrument itself (a tax rather than a ban) is not as strict.

Tatiana Homonoff

New York University

Robert F. Wagner School of Public Service 295 Lafayette Street, 2nd Floor

New York, NY 10012

and NBER

tatiana.homonoff@nyu.edu

Lee-Sien Kao

ideas42

80 Broad St, Floor 30

New York, NY 10004

lee-sien@ideas42.org

Javiera Selman

New York University

Robert F. Wagner School of Public Service

295 Lafayette Street, 2nd Floor

New York, NY 10012

jselman@nyu.edu

Christina Seybolt

Social Impact, Inc.

2300 Clarendon Blvd \#1000

Arlington, VA 22201

christinaseybolt@gmail.com
\end{abstract}




\section{Introduction}

Many recent government and corporate policies aimed at reducing a variety of negative externalities include regulations that ban the provision of externality-generating products. However, these policies often ban only a narrow subset of products associated with the underlying externality. For example, the Department of Justice banned "bump stocks" which assist in rapid fire shooting after a Las Vegas mass shooting (White, 2019) rather than placing stricter regulations on all assault weapons. Similarly, Starbucks recently banned distribution of plastic straws at its stores to reduce environmental waste (Rochman, 2018) and New York City attempted to pass a restaurant ban on sugar-sweetened beverages over 16 ounces to curb obesity (Grynbaum, 2014).

But do these policies achieve their intended goal? One concern with narrowly-defined bans is that they may leave close undesirable substitutes unregulated, creating unintended consequences of the policies. In the case of assault weapon bans, gun manufacturers devised several adaptations to comply with the ban while still providing consumers with a nearly identical product. ${ }^{1}$ Along with the plastic straw ban, Starbucks introduced a new strawless "cold-cup lid" which required more plastic than the original lid and straw combined (Britschgi, 2018). ${ }^{2}$

One potential reason for the relatively narrow scope of these types of regulations is that, in many cases, it is politically infeasible to ban a broader class of products, such as a ban on all sugarsweetened beverages (Brescoll, Kersh and Brownell, 2008). However, there are several cases of governments successfully passing incentive-based policies, such as a tax or a fee, on a wider range of products. For example, many state and local governments levy taxes on sugar-sweetened beverages (of all sizes and sold in all establishments) (Allcott, Lockwood and Taubinsky, 2019; Cawley et al., 2019). These policies are less strict in one sense - all products are still available for consumption but may nonetheless be more effective since they leave fewer substitutes unregulated.

We examine the relative effectiveness of these two policy designs - a narrowly-defined ban versus a tax on a broader base of products - in the context of recent regulations on the use of disposable

\footnotetext{
${ }^{1}$ For example, gun manufacturers created a device called a "binary trigger" which serves the same purpose as a bump stock, but circumvents the federal ban (White, 2019).

${ }^{2}$ The New York City ban was ruled unconstitutional before it was ever in effect, however, lab experiments suggests that if retailers had responded to the policy by bundling smaller sodas together at the same price as a larger, banned soda (i.e., one 24 ounce soda versus two 12 ounce sodas), this could lead to higher consumption of soda (Wilson, Stolarz-Fantino and Fantino, 2013).
} 
shopping bags. ${ }^{3}$ Disposable bag regulations were first introduced in the United States only a little more than a decade ago, but have experienced rapid growth in this short period: as of 2017, one out of six people lived in a jurisdiction covered by a state or local government ordinance regulating plastic bags (Wagner, 2017). Regulations of disposable bags commonly take two forms: a ban on plastic bags (a subset of all disposable bags) or a tax on all disposable bags. To date, no regulations have considered an outright ban on all disposable shopping bags.

In this paper, we examine the effect of two such regulations in the city of Chicago. In 2015, Chicago passed an ordinance banning all single-use plastic bags less than 2.25 mils thick - the most common design of disposable bag regulations in the US - leaving all other types of disposable bags unregulated. ${ }^{4}$ This policy was repealed starting in 2017 and replaced with a 7 -cent tax on all disposable bags (both plastic and paper bags of all thicknesses) one month later.

To estimate the effect of these policies on disposable bag use, we collected a unique individuallevel data set on bag use for 24,002 shoppers by observing customers at grocery stores in the city of Chicago ("treatment" stores) and in the surrounding suburbs that were not regulated by either policy ("control" stores) from November 2016 to March 2018. This sample period spans three policy regimes: (i) the Chicago plastic bag ban, (ii) a period of no regulation, and (iii) the Chicago tax on all disposable bags, allowing us to estimate the relative effectiveness of the two regulation designs as well as the impact of the repeal of the ban and the implementation of the tax using a difference-in-differences design.

We find that disposable bag use in Chicago remained high during the plastic bag ban: 82 percent of customers in Chicago used an unregulated disposable bag - either a paper bag or a plastic bag thicker than 2.25 mils - which continued to be distributed for free during the ban. Additionally, we observe no change in the proportion of customers using a disposable bag after the repeal of the ban. In contrast, we find that the implementation of the tax in the subsequent months led to a large decrease in disposable bag use. ${ }^{5}$ When comparing the relative effectiveness of the two policies, we find that the proportion of customers using a disposable bag decreased by 33 percentage points

\footnotetext{
${ }^{3}$ In this study, we define disposable bags to include all plastic bags, both low- and high-density polyethylene (which we refer to as "thin" and "thick" plastic, respectively), and paper bags provided by the retailer for immediate use.

${ }^{4}$ Similar stand-alone bans are the statewide regulation of New York and Delaware and will soon be in Connecticut (July 2021) as well.

${ }^{5}$ While the estimate of the repeal of the ban is likely a lower bound estimate for the effect of the ban's implementation due to potential habit formation, the estimate of the effect of the tax is likely an underestimate for the same reason.
} 
during the tax relative to during the ban leading to a decrease of just over one disposable bag per trip. This effect appears largely persistent: the reduction in the share of customers using a disposable bag remained large and statistically significant throughout the first year of tax's implementation, though we do observe a rebound effect equivalent to roughly one quarter of the initial effect of the tax by the end of the sample period.

The results on overall disposable bag use suggest that the tax was significantly more effective than the ban at reducing disposable bag use. Moreover, these results mask an important unintended consequence of the plastic bag ban. When we consider the effects of the two policies on the type of disposable bag used, we find that the ban successfully eliminated lightweight plastic bag use (as designed). However, it led retailers to provide free thick plastic bags with a thickness roughly just over the 2.25 mils defined in the ban, five times the amount of plastic in a standard plastic grocery bag. During the ban, over 40 percent of customers shopping in Chicago used a free thick plastic bag with the remaining disposable bag users taking a paper bag. These thick plastic bags were then phased out once the ban was repealed.

Taking the composition of bags used into account, we find that during the tax policy, customers used significantly less plastic and paper than during the ban - a decrease equivalent to the amount of plastic in roughly four thin plastic bags and one paper bag per trip. As a result, analyses that take into account the composition of bags used (rather than just the number of disposable bags used), including those considering the life-cycle environmental impact of the different types of bags used, substantially increase our estimate of the relative effectiveness of the tax compared to the ban. While we do not have data on bag reuse, our estimates decrease only slightly if we assume that thick plastic bags and paper bags are reused, for example, as bin liners - in fact, customers must reuse these bags at least six times as often as thin plastic bags to no longer statistically conclude that the tax is more effective than the ban, far more often than suggested in the literature (Prendergast, Wai Ng and Lee Leung, 2001).

This paper contributes to a recent literature on the effect of disposable bag regulations on consumer behavior by comparing the relative effectiveness of two of the most common regulation designs. Previous research in the US finds decreases in disposable bag use in response to disposable bag taxes as well as "hybrid bans" that are similar in magnitude to our estimates of the effect of the Chicago tax: Homonoff (2018) finds that a five-cent disposable bag tax in the DC area led to 
a 42 percentage point decrease in disposable bag use and Taylor and Villas-Boas (2016) estimate a 35 percentage point decrease in response to a California policy that combined a plastic bag ban with a five-cent paper bag fee. ${ }^{6}$ However, to our knowledge, we are the first paper to rigorously evaluate the effect of a stand-alone ban on plastic bags in the US. ${ }^{7}$ Importantly, we are able to compare the two competing policy designs within the same city rather than relying on cross-state comparisons which may be biased due to differences in the populations. Our findings suggest that the success of the policies estimated in prior research relies on the fact that those policies regulated all forms of disposable bags. We find that plastic bag bans - stricter, but more narrowly-defined regulations that leave close substitutes unregulated - are significantly less effective at reducing the use of disposable bags than disposable bag taxes and, in fact, may increase overall environmental costs by changing the composition of types of bags used.

Our paper also contributes to a broader literature on the unintended consequences of bans on goods associated with negative externalities. This literature largely focuses on behavioral responses taken on the part of the consumer that undermine the effectiveness of the policy. For example, school bans on soda lead to increases in soda purchased for the home (Lichtman-Sadot, 2016), state bans on payday loans decrease payday loan use, but increase the use of pawn shops (Bhutta, Goldin and Homonoff, 2016), and a Mexican policy that banned drivers from using their car one day per week led to the unintended consequence of increasing the number of cars in circulation (Davis, 2008). In the context of disposable bag regulations, partial regulation may generate environmental leakage. ${ }^{8}$ For example, Taylor (2019) finds that plastic bag bans coupled with paper bag fees lead to increases in sales of plastic trash bags, partially offsetting the environmental benefits of the policy. Most closely related to our paper, Adda and Cornaglia (2010) compare the relative effectiveness of taxes and bans on tobacco use at reducing second-hand smoking and find that excise taxes on cigarettes decrease exposure to second-hand smoke, while restaurant and workplace smoking bans increase second-hand smoking by increasing smoking in the home. Our findings complement these

\footnotetext{
${ }^{6}$ Additionally, several studies outside of the US find significant decreases in disposable bag use after the implementation of policies that charge for disposable bags (Poortinga, Whitmarsh and Suffolk, 2013; Jakovcevic et al., 2014; Rivers, Shenstone-Harris and Young, 2017; Cabrera, Caffera and Cid, 2020).

${ }^{7}$ Several developing countries have also implemented plastic bag bans (see Nielsen, Holmberg and Stripple (2019) for a review); however, these studies highlight that one of the key failures of these policies is the lack of enforcement (Gupta, 2011; Bharadwaj, Baland and Nepal, 2020), suggesting that the findings may not be informative in the US context where enforcement levels are higher.

${ }^{8}$ Environmental leakage occurs when partial regulation of environmentally harmful products directly results in increased consumption of the products in unregulated parts of the economy (Fowlie, 2009).
} 
various results on regulation-avoidant behavior on the part of the consumer, by demonstrating similar behavior on the side of the producer: the introduction of free thick plastic bags.

This paper is organized as follows. Section II provides an overview of disposable bag ordinances in the US as well as specific details on the policies in the city of Chicago. Section III describes the data used in our analyses. Section IV presents estimates of the effect of the two policies on disposable bag use. Section V concludes.

\section{Institutional Background}

\section{A. History of Disposable Bag Ordinances in the United States}

Each year, Americans consume an estimated one hundred billion plastic bags (Clapp and Swanston, 2009; Wagner, 2017). While plastic bags are recyclable, only 10 percent of single-use plastic (which includes plastic bags, sacks, and wraps) is ultimately recovered (USEPA, 2018). Unrecycled bags frequently end up in landfills, clog storm drains, or find their way into local waterways or trees costing local US governments between 3 and 8 billion dollars per year to clean up (Taylor and Villas-Boas, 2016) and leading to urban flooding in developing countries (Pervin et al., 2020). Over the past decade, many state and local governments throughout the United States have passed laws or ordinances regulating the use of single-use disposable bags in an attempt to curb these environmental costs. As of September 2017, one out of every six individuals in the US lived in a jurisdiction with a disposable bag ordinance (Wagner, 2017).

Disposable bag legislation has largely been driven by local governments - as of August 2019, over 450 local ordinances restricting the use of plastic bags were in place in 28 states throughout the country. Seven states have passed statewide legislation as well including California, Connecticut, Delaware, Maine, New York, Oregon, and Vermont. Additionally, Hawaii has a de facto statewide law since all counties in the state have implemented a disposable bag regulation. ${ }^{9}$ These policies commonly take one of three forms: (i) a stand-alone plastic bag ban, (ii) a disposable bag fee, or (iii) a hybrid ban plus fee. ${ }^{10}$

\footnotetext{
${ }^{9}$ Details on the number of regulations are based on the authors' calculations from data collected from databases of state regulations, such as the National Conference of State Legislatures and plasticbaglaws.org, as well as local news articles.

${ }^{10}$ Additionally, as of August 2019, seventeen states had passed a preemptive "ban on bans" which prohibited laws
} 
The first plastic bag regulation in the United States was implemented in San Francisco in 2007. ${ }^{11}$ Importantly, San Francisco was restricted in its choice of policy design by California's State Assembly Bill 2449 which banned the use of fees on single-use plastic bags, making a ban San Francisco's only option for regulating the use of plastic bags (Romer and Tamminen, 2014). The ban applied to thin, single-use plastic bags less than 2.25 mils thick (roughly the thickness of a commercial garbage bag and the definition of single-use plastic bags used in the California law), but left the use of all other bags, such as paper bags, unregulated. Most states do not pose similar restrictions on plastic bag fees. Nevertheless, bans like the one in San Francisco are currently the most common disposable bag regulation in the US: almost all existing state and local ordinances include a ban on single-use plastic bags, with many policies using the same 2.25 mils cutoff to define "single-use". Stand-alone plastic bag bans can be found in 26 states and comprise over half of all local ordinances. ${ }^{12}$ Additionally, by the middle of 2021 , stand-alone bans will be the effective statewide bag regulation in New York, Delaware, and Connecticut.

An alternative policy places a tax or fee on each disposable bag a customer uses rather than prohibiting the use of plastic bags. Washington, DC became the first US city to implement a policy of this type with the passage of the Anacostia River Cleanup and Protection Act in 2010. This ordinance required that grocery stores must charge a five-cent tax on all plastic and paper bags. Policies with this incentive-based design are much less common - fewer than 30 local ordinances charge for plastic bags instead of banning them altogether.

A third policy design, often referred to as a hybrid ban or a "second generation ban" (Romer and Tamminen, 2014), couples a plastic bag ban with a paper bag fee, typically in the range of five to fifteen cents per bag. Originally designed in response to a California supreme court ruling requiring all plastic bag regulations to be coupled with regulations on paper bags, this policy has also become a popular design outside of California. Plastic bag bans with paper bag fees currently exist in fifteen states and are the statewide policy choice of California, Maine, Oregon, and Vermont.

banning the use of plastic bags.

${ }^{11}$ One exception was a "soft ban" on plastic bags initiated in Maine in 1989 in which retailers were to required to offer only paper bags unless a customer specifically requested a plastic bag (Wagner, 2017). The policy was repealed three years later.

${ }^{12}$ To compute this estimate, we identified the number of ordinances by type in each state that has a disposable bag legislation. This estimate includes all ordinances that are passed before or after statewide policy but does not consider the size of the population affected by each local ordinance, only the number of ordinances of each regulation design that have been successfully passed. 


\section{B. Chicago Disposable Bag Ordinances}

In August 2015, the city of Chicago introduced its first policy regulating the use of disposable shopping bags: a stand-alone ban on single-use plastic bags. Like many other plastic bag bans throughout the country, the ban applied to thin, single-use plastic bags defined as plastic bags less than 2.25 mils thick. The policy first applied only to large stores (defined as over 10,000 square feet), but was expanded to include all chains and franchises in August 2016. ${ }^{13}$ Stores that provided plastic bags prior to the ban were required to provide reusable bags, recyclable paper bags, or commercially compostable plastic bags once the ban was implemented.

Importantly, the ban did not apply to other types of disposable bags including plastic bags thicker than 2.25 mils or paper bags. As a result, stores that previously offered free paper bags continued to do so. Additionally, several of the larger retailers that had previously offered thin plastic bags instead began offering customers free thick plastic bags with a thickness roughly just over the threshold designated by the ban. ${ }^{14}$

Recognizing this unintended response by the retailers, in November 2016, the Chicago City Council repealed the ban effective January 1, 2017. In its place, the council implemented a new regulation, the Chicago Checkout Bag Tax,${ }^{15}$ which levied a 7 -cent tax on all disposable bags. Five cents from each taxed unit was paid to the city while the remaining two cents remained with the retailer. Customers purchasing groceries with benefits from the Supplemental Nutritional Assistance Program or a similar governmental food assistance program were not subject to the tax. ${ }^{16}$ The tax did not apply to plastic bags used to carry loose bulk items (such as fruits and vegetables) or used to segregate food that could contaminate other merchandise (such as meat). Reusable bags with a price of 50 cents or more were exempt from the tax. This tax was originally scheduled to go into effect the same date of the ban repeal, but was postponed until February 1, 2017, leaving one month (January 2017) without any disposable bag regulation.

\footnotetext{
${ }^{13}$ The ban applied to all retail establishments selling perishable or non-perishable goods, including but not limited to clothing, food and personal items, but not to restaurants or any store that is not a chain store or franchise with "chain" defined as three or more stores with common ownership.

${ }^{14}$ Similar behavior among retailers was reported after a plastic bag ban in Honolulu County, Hawaii in 2015 (Solomon, 2016) and in response to a hybrid ban in California (Gardinier, 2019). Taylor and Villas-Boas (2016) find that different retailers make different decisions in response to a hybrid ban in Richmond, CA - one retailer provided only paper bags, while a discount store offered both paper and thicker plastic. Unlike in Richmond, we found more uniformity in retailer behavior across the largest chains in Chicago.

${ }^{15}$ Chicago, Illinois, Municipal Code ch. 3-50.

${ }^{16}$ Chicago, Illinois, Amendment of Municipal Code ch. 11-4 by adding Article XXIII.
} 


\section{Prior Research on Effectiveness of Disposable Bag Ordinances}

There is an ongoing policy debate about whether and how to implement disposable bag regulations in the US. However, there is limited rigorous research investigating how policies to reduce disposable bag use affect consumer behavior. Most empirical studies report simple differences, i.e., outcomes before and after a policy change, failing to account for confounding factors such as changes in social norms about the acceptability of using disposable bags that may have motivated policy interventions in the first place. As a result, reported reductions in disposable bag use may be upward biased (Rivers, Shenstone-Harris and Young, 2017).

There are two notable exceptions in the US context. Taylor and Villas-Boas (2016) estimate the effect of a hybrid plastic bag ban plus five-cent minimum paper bag fee and Homonoff (2018) estimates the effect of a five-cent tax on all disposable bags (both paper and plastic). ${ }^{17}$ Both studies collect data on individual-level bag use observed at stores in regulated and unregulated cities before and after the policy was implemented. Though these studies evaluate policies with different designs that were implemented in different locations, both find that the policy in question led to a very large decrease in disposable bag use - the hybrid ban led to a 35 percentage point decrease in the proportion of customers using a disposable bag, while the tax on all disposable bags led to a 42 percentage point decrease. Though the effects of the two policies on the likelihood of using any disposable bags were quite similar, the policy choice did impact the type of bag that a customer used. Under the tax policy, most customers who continued to use a disposable bag used a thin plastic bag when available. In contrast (and by construction), customers who continued to use disposable bags during the hybrid ban primarily used paper bags. ${ }^{18}$ If plastic bags are more environmentally harmful than paper bags, this evidence suggests that hybrid bans are more effective at reducing these costs; however, paper bags have their own environmental impact making the relative effectiveness of the two policies unclear. ${ }^{19}$

There are also several studies outside of the US that estimate the effect of disposable bag charges on bag use using causal inference methods. Jakovcevic et al. (2014) use a difference-in-differences

\footnotetext{
${ }^{17}$ The policy evaluated in Taylor and Villas-Boas (2016) was implemented in Richmond, California in 2014, while the policy evaluated in Homonoff (2018) was implemented in Montgomery County, Maryland in 2012.

${ }^{18}$ One exception was at a discount chain that offered a popular alternative, a 15 -cent thick-plastic reusable bags (Taylor and Villas-Boas, 2016).

${ }^{19}$ For example, production of paper bags requires more energy and creates more air and water pollution than plastic bag production; additionally, paper bags require more energy to recycle and transport (Taylor and Villas-Boas, 2016).
} 
research design to study the effect of a charge for disposable bags in Argentina using observational data. Poortinga, Whitmarsh and Suffolk (2013) and Rivers, Shenstone-Harris and Young (2017) use a similar research design to study the effect of a $5 \mathrm{p} /[5$ cent $]$ tax on disposable bags in England and Toronto, respectively, but rely on survey data on typical bag use rather than observational data from grocery stores. All three studies find significant decreases in disposable bag use, though the decreases are somewhat smaller than the US studies. In contrast, recent work by Cabrera, Caffera and Cid (2020) uses data provided by national supermarket chain in Uruguay to evaluate the staggered roll-out of a policy that charged roughly 7 cents for disposable bags and finds that the policy led to a 70 to 85 percent decrease in disposable bag use.

In spite of the prevalence of stand-alone bans, to our knowledge, our study provides the first evaluation of this policy design. An important distinction between stand-alone bans versus hybrid bans or stand-alone taxes is that under the latter two policies, all disposable bags - thin plastic, thicker plastic, and paper bags - fall under the regulation. In contrast, stand-alone bans on plastic bags leave potential close substitutes, i.e., other types of disposable bags, unregulated. Therefore, it may be inappropriate to extrapolate the effects of disposable bag regulations of these different designs to stand-alone bans. Additionally, Chicago is one of the few cities that has experimented with two types of bag regulations: a stand-alone ban and a stand-alone tax. This allows us to compare the two types of policies in the same city (in fact, the exact same stores) rather than relying on a cross-state comparison.

\section{Data}

To evaluate the effectiveness of the two disposable bag regulations implemented in Chicago, we collect individual-level data on bag use among customers at grocery stores in the City of Chicago who were subject to the disposable bag regulations, as well as customers shopping in a set of grocery stores located in the same county as Chicago but just outside the city limits who were not subject to any disposable bag regulations during the period of analysis. Our primary data set is comprised of data collected during three time periods: November-December 2016 (the final months of the plastic bag ban), January 2017 (the month in which stores were not subject to any disposable bag regulation), and February-March 2017 (the first months of the tax). We supplement 
our main data set with follow-up collection periods roughly once per quarter for the first year of the tax's implementation to estimate the persistence of any estimated effect over time. Specifically, we collect data in three additional waves: May 2017 (quarter 2), October-November 2017 (quarter 3), and January-March 2018 (quarter 4).

The sample includes data on bag use from twelve grocery stores: eight stores in Chicago and four stores located in the surrounding suburbs within Cook County, Illinois which did not implement any disposable bag regulations. ${ }^{20}$ The stores in the sample were limited to large chain grocery stores for ease of comparison across locations. Comparison stores in the suburbs were chosen for similarity with the Chicago stores on ZIP code-level demographic characteristics; for example, all stores were located near a public bus stop and also had a parking lot. Half of the stores in each group (treatment and control) were selected from ZIP codes with a median income below that of Cook County (\$61,405 in 2017) and half were selected from ZIP codes with median incomes above the countywide median. The average census tract median income was roughly $\$ 63,000$ in control stores and $\$ 75,000$ in treatment stores (ACS, 2017).

Researchers were hired and trained by staff at the University of Chicago to collect the data used in this study. Data collectors were instructed to stand by the exit of a sample store and record individual-level data on the number and type of bags each customer used (thin plastic, thick plastic, paper, or reusable), as well as visually assessable demographic characteristics, such as sex and race, of all customers exiting the store. These researchers were trained not to interact with customers so as to minimize any Hawthorne effects. ${ }^{21}$ They were also given instructions on how to collect data (e.g., how to classify bags as reusable, how to identify and record double-bagging, that they should exclude plastic bags used for produce or meat that are not regulated by the policies) to ensure uniformity of data collection across researchers. ${ }^{22}$ Researchers visited a given store for either 40 minutes, or for the observation of 100 consumers, whichever came first. The visits took place during either a daytime (ten in the morning to four thirty in the afternoon) or evening (four thirty in the afternoon to eight at night) shift during weekdays only. Each of the 12 sample stores received an average of 12 visits during the main sample period (November 2016 to March 2017) and

\footnotetext{
${ }^{20}$ Suburban sample stores were located in the cities of Evergreen Park, Melrose Park, North Riverside, and Oaklawn. See Figure 1 for a map of store locations.

${ }^{21}$ For example, they were encouraged to wear ear buds or bring a book so as not to appear out of place.

${ }^{22}$ Additionally, our main specifications include individual data collector fixed effects to control for any remaining differences across researchers.
} 
an additional 12 visits during the follow-up period (May 2017 to March 2018). Our final sample includes data on roughly 1,000 customers per store in each sample period for a total of 24,002 individual customers.

Table 1 presents store-level statistics on the race and sex of customers in our sample as well as the median income in the ZIP code in which the store is located. In Chicago, the racial composition of the customers in our sample closely tracked neighborhood income with higher-income stores serving predominantly white customers, while customers in lower-income stores were almost exclusively non-white. Customers shopping in a given suburban store were not as racially homogeneous as those in Chicago, nor did racial composition correlate as closely with neighborhood income. Most sample stores had a higher proportion of female customers ranging from one half to two thirds of all customers.

\section{Results}

As mentioned in the previous section, our data spans three different policy regimes in Chicago: a stand-alone ban on thin plastic bags, a tax on all disposable bags, and a period in between with no regulation. This section empirically estimates the relative effectiveness of the two policy designs.

Table 2 presents summary statistics on bag use separately for sample stores in Chicago and the surrounding suburbs in each of the three policy regimes. Stores located in Cook County but outside of Chicago were not subject to any disposable bag regulation. Column 1 shows that during our first sample period (the last months of the Chicago ban) 90 percent of customers in unregulated stores in the suburbs used at least one disposable bag during the observed shopping trips with the average customer using three disposable bags per trip. ${ }^{23}$ Eight percent of customers used a reusable bag and five percent used no bags at all. Notably, columns 2 and 3 show that these statistics change very little across policy regimes: the proportion of customers using a reusable bag remains between 90 and 92 percent throughout the sample period.

Columns 4 through 6 present the same statistics for sample stores in Chicago. Here we find a slightly lower, but still large fraction of customers using disposable bags during the ban -82 percent of Chicago customers used at least one disposable bag with the average customer using two

\footnotetext{
${ }^{23}$ As previously mentioned, we define disposable bags as any bag (paper or plastic) that is distributed for free by the store. We define reusable bags as heavier-weight bags sold by the store or tote bags brought from home.
} 
disposable bags per trip. Correspondingly, we observe a slightly higher proportion of customers using a reusable bag (13 percent) or no bag at all (9 percent). Unlike in the suburban stores, we do observe changes in bag use in Chicago over time. While the rate of disposable bag use remains constant during the month after the ban is repealed, we observe a large decrease in disposable bag use once the tax was implemented.

\section{A. Effects on Disposable Bag Use}

To estimate the effect of each policy on various measures of bag use, we employ a difference-indifferences specification. We begin by estimating the following regression:

$$
Y_{i s h t}=\alpha+\beta_{1} \text { ChicagoxBan }_{s t}+\gamma_{1} \text { Ban }_{t}+\beta_{2} \text { ChicagoxTax }_{s t}+\gamma_{2} \operatorname{Tax}_{t}+\lambda Z_{s}+\eta X_{i}+\rho D_{h}+\epsilon_{i s h t}
$$

$Y_{i s t}$ is a measure of bag use for individual $i$ shopping in store $s$ during time period $t$. Chicago is an indicator for shopping in a store in Chicago, Ban is an indicator for shopping during the ban (November-December 2016), and Tax is an indicator for shopping during the first quarter of the tax (February-March 2017). The model also controls for store fixed effects $\left(Z_{s}\right)$, customer demographic characteristics $\left(X_{i}\right)$, and an indicator for shopping during daytime versus evening hours $\left(D_{h}\right) .{ }^{24}$ The coefficient on ChicagoxBan $\left(\beta_{1}\right)$ is the difference-in-differences estimate measuring the effect of the ban compared to the period immediately after the ban was repealed during which there was no disposable bag regulation in Chicago (January 2017). Similarly, the coefficient on ChicagoxTax $\left(\beta_{2}\right)$ estimates the effect of the implementation of the tax relative the the no regulation period.

The key identifying assumption in our empirical strategy is that the trends in bag use would have been the same in treatment and control stores were it not for the policy change, i.e., the parallel trends assumption. One common approach used to assess the validity of this assumption is to demonstrate that there are no differential pre-trends in the time periods leading up to the policy change. A separate, but related violation of our identifying assumption occurs if there are anticipation effects (Malani and Reif, 2015), for example, if shoppers in Chicago begin using

\footnotetext{
${ }^{24}$ We present standard errors clustered at the store level (as they are more conservative), though our results are robust to using wild-bootstrap p-values to obtain t-statistics from pseudo standard errors (Cameron, Gelbach and Miller, 2008) to account for the fact that we only have 12 clusters in the data.
} 
reusable bags in advance of the tax's implementation. Unfortunately, our data collection spanned only a few weeks in the ban period and the no regulation period, so we are unable to test for pre-trends or anticipation effects. Nevertheless, prior research in the US and Latin America show no evidence of differential pre-trends in advance of similar disposable bag regulations (Taylor and Villas-Boas, 2016; Cabrera, Caffera and Cid, 2020), though the latter study does show some evidence of anticipation effects. We believe that anticipation effects are less likely in our setting since Chicago had implemented the ban over a year before the tax's implementation (the policy change we study); however, if there are anticipation effects, our estimates of the relative effect of the tax should be viewed as an underestimate of the effect of the policy.

Panel A of Table 3 presents the results of this analysis for the four bag use variables in Table 2. We first consider the estimates of the effect of the ban repeal $\left(\beta_{1}\right)$. Column 1 shows that repealing the ban had no effect on the likelihood of using a disposable bag - the point estimate is less than one percentage point and is not statistically significant. Column 2 shows a similarly small and not statistically significant decrease in the number of disposable bags as a result of the ban repeal. Somewhat unsurprisingly given these null effects on disposable bag use, columns 3 and 4 show no evidence of a statistically significant change in the likelihood of using a reusable bag or using no bags at all.

Turning to the estimates of the effect of the implementation of the $\operatorname{tax}\left(\beta_{2}\right)$, we observe a very different pattern. Column 1 shows that during the first quarter of the tax's implementation, the likelihood of a customer using a disposable bag decreases by 33 percentage points relative to the no regulation period. This corresponds to a decrease in just over one bag per shopping trip (column 2). The tax led to an increase of 17 percentage points in the likelihood of using a reusable bag (column 3) and an increase of 16 percentage points in the likelihood of using no bags at all (column 4).

When comparing estimates of $\beta_{1}$ and $\beta_{2}$, it is important to note that we estimate the impact of the initial implementation of the tax but the repeal of the ban, and that the change in behavior resulting from the introduction versus the repeal of the ban need not be symmetric. For example, if the behavioral change induced by the ban changed customer habits, effects of the ban might persist after its repeal. Rivers, Shenstone-Harris and Young (2017) find evidence against this behavior after the repeal of the Toronto bag tax: reusable bag use increased following the implementation of a five-cent tax in Toronto, but this effect did not persist after the tax was repealed. However, given 
that in Chicago the tax was announced at the same time as the repeal of the ban, this announcement may have mitigated a rebound in disposable bag use during the period between the two policies. By the same argument, if the ban did indeed lead to a decrease in disposable bag use that persisted after the repeal, the estimate of the effect of the tax is likely to be underestimated: customers who developed a habit of avoiding disposable bags in response to the ban may also have been customers who would have responded to the tax.

Nonetheless, the high rate of disposable bag use observed in Chicago during the ban (82 percent) provides us with a useful upper bound of the effect of the ban: if all customers used a disposable bag in the absence of the ban and every customer that stopped using disposable bags as a result of the ban continued to do so after the ban was repealed, the introduction of the ban led to at most a decrease of 18 percentage points in the proportion of customers using a disposable bag. This suggests that even with extreme assumptions about the asymmetry of the introduction and repeal of the ban, the tax was almost twice as effective as the ban at reducing the proportion of customers using a disposable bag.

To avoid concerns about behavior in the no regulation period, Panel B of Table 3 compares the relative effectiveness of the ban and the tax by estimating the following model:

$$
Y_{\text {isht }}=\alpha+\beta \text { ChicagoxTax } \operatorname{Tax}_{s t}+\gamma \operatorname{Tax}_{t}+\lambda Z_{s}+\eta X_{i}+\rho D_{h}+\epsilon_{i s h t}
$$

In this regression, we exclude data from January 2017 so that the reference group consists of customers observed during the last months of the ban rather than the period with no regulation, allowing us to compare bag use during the ban directly to bag use during the tax. All variables are defined as those in equation (1). As a result, $\beta$ measures the effectiveness of the tax relative to the ban.

Column 1 shows that the proportion of customers using a disposable bag was 33 percentage points lower during the tax than during the ban. On average, customers used roughly one less disposable bag during the tax relative to during the ban (column 2). The decrease in disposable bag use was driven roughly equally by a switch to reusable bags and the choice to forgo bags altogether (columns 3 and 4). Taken together, these results suggest that the tax was substantially more effective at reducing disposable bag use than the ban. 


\section{B. Composition of Disposable Bags}

The previous section shows large differences in the relative effectiveness of the ban and the tax on the proportion of customers using a disposable bag and the number of bags used. However, these outcomes group all types of disposable bags (paper versus plastic, thin versus thick) together, potentially masking important differences in the composition of disposable bags used under different policies.

Figure 2 presents the proportion of customers in our sample that used a disposable bag during each of the three policy regimes - ban, no regulation, and tax - separately for sample stores in Chicago and the surrounding suburbs. The height of each bar represents the proportion of customers using at least one disposable bag, while the shading describes the type of disposable bag used: thin plastic, thick plastic, paper, or a combination of two or more.

The first bar, for example, shows that during the last months of the Chicago ban, 90 percent of customers in unregulated stores in the suburbs used at least one disposable bag during the observed shopping trips. The vast majority of customers ( 81 percent) used only thin plastic bags, 4 percent used only paper bags, and 5 percent used both paper and plastic bags. No customers in suburban stores used a thick plastic bag, suggesting that these stores did not offer that option. The next two bars show that bag use - both the fraction of customers using any disposable bags and the composition of types of bags - is largely unchanged across the three policy regimes for stores in the suburbs.

The following three bars repeat the analysis for stores in Chicago. As shown in Table 2, stores in Chicago experience a slightly lower, but still large fraction of customers using disposable bags in Chicago during the ban -82 percent of customers used at least one disposable bag. However, the composition of disposable bags used during the ban differed greatly across locations. In Chicago, no customers used a thin plastic bag, suggesting that the ban was implemented as intended. However, unlike in the suburbs, a substantial fraction of Chicago customers used a thick plastic bag (41 percent) and a much higher proportion used paper bags (also 41 percent). Once the ban was lifted, the proportion of customers using thick plastic or paper bags decreased and thin plastic bags were reintroduced, though the proportion of customers using any disposable bag remained unchanged 
until the implementation of the tax..$^{25}$

Table 4 compares bag use by type during the ban to bag use during the tax as in equation (2). ${ }^{26}$ Each column estimates the relative effects of the two policies on the likelihood of using a specific type of disposable bag: thick plastic bags, thin plastic bags, paper bags, or a mix of types. Under the tax policy, customers were 33 percentage points less likely to use only thick plastic bags and 27 percentage points less likely to use only paper bags relative to the bag use under the ban. This was partially offset by a 23 percentage point increase in the proportion of customers using only thin plastic bags and a 3 percentage point increase in the proportion of customers using multiple types of disposable bags. These results suggest that the policy choice affects not only the prevalence of disposable bag use, but the composition of bags used and that ignoring the unintended consequence of the introduction of thicker plastic bags during the ban would underestimate the costs associated with the policy. We address this question directly in the following section.

\section{Environmental Footprint}

As mentioned in Section II, plastic bags and paper bags each come with their own set of environmental costs - for example, plastic bags generate more litter and are more difficult to recycle, while paper bags require more energy to produce and that production creates more air and water pollutants. Therefore, to assess the effectiveness of the policies in question on overall environmental costs, we must understand the relative costs of the different types of bags used.

In this section, we estimate the relative amount of plastic and paper used under the different policies. Additionally, we use estimates of the relative impact of the three types of disposable bags on global warming potential as measured by the UK's Environment Agency (Edwards and Fry, 2011). This report assesses the life-cycle environmental impacts of the production, use, and disposal of different types of shopping bags. The report finds that the environmental costs of paper bags are four times that of thin plastic bags and that the costs of thick plastic bags are five times

\footnotetext{
${ }^{25}$ While the use of thick plastic bags decreased after the repeal of ban, 28 percent of customers shopping in Chicago used a thick plastic bag in the month after the repeal. This number decreased to only 7 percent during the tax. In fact, no customers in our data used a thick plastic bag after March of 2017. This is consistent with a scenario in which stores continued to offer thicker bags after the repeal so as to deplete their stores, but that this type of bag was no longer available once the original supply ran out.

${ }^{26}$ Importantly, this specification excludes the period in which stores were beginning to phase out the use of thick plastic bags (the no regulation period), but had not yet completed the process.
} 
that of thin plastic bags.

An important limitation of this analysis is that life-cycle assessments are based on a specific locale. For example, costs associated with the transportation of bags are a key contributor to the overall environmental impact of a bag and these costs may differ across locations, biasing our estimate of the relative environmental impact of paper versus plastic bags. A second limitation is that the analyses in Edwards and Fry (2011) do not provide estimates of absolute costs of each type of bag, only relative costs of one type of bag versus another. As a result, we are only able to estimate the relative environmental costs of the bags used under the different policy regimes, rather than absolute costs.

Table 5 estimates the effect of the tax relative to the ban on environmental costs. We first consider the relative effect of the tax on the amount of plastic and paper used. We use estimates from Edwards and Fry (2011) to create a measure of total plastic used per shopping trip where the units are in numbers of thin plastic bags (column 1). Specifically, we assume that thick plastic bags generate five times as much plastic as thin plastic bags - this assumption is equivalent to assuming that thick plastic bags have a thickness just over the 2.25 mil threshold and that thin plastic bags have a thickness of 0.5 mils, a common estimate of the thickness of standard thin plastic bags. Column 2 estimates the relative effectiveness of the policies on the amount of paper used per shopping trip where units are in number of paper bags. The results show that during the tax, customers used significantly less paper and plastic: the average customer used 0.7 fewer paper bags and an equivalent of almost four fewer thin plastic bags per trip during the tax relative to during the ban.

Column 3 combines these estimates to create an overall measure of the environmental footprint generated by the composition of disposable bags used using the estimates from Edwards and Fry (2011). Specifically, the outcome variable is measured in units of cost generated from one thin plastic bag. For example, a customer who uses five thin plastic bags generates five units of cost; similarly, a customer who uses one thin plastic bag and one paper bag also creates five units of cost since the environmental cost of one paper bag is four times that on one thin plastic bag. We find that, relative the ban, the tax led to a reduction in environmental costs equivalent to the use of 6.5 thin plastic bags per shopping trip. As noted above, if the relative environmental impact of paper versus plastic bags estimated in (Edwards and Fry, 2011) in the UK context are not representative 
of relative costs in Chicago, this will bias our estimate of the relative effect of the tax versus the ban on the overall environmental footprint. However, given that columns 1 and 2 show a reduction in both the amount of plastic used and the amount of paper used, any bias will affect the magnitude of our estimate - which could be an over- or underestimate - but not the direction of the estimate.

\section{Effect of Tax over Time}

This section uses additional data collected quarterly over the following year to assess whether the initial effect of the tax persisted over time. It is worth noting that the ban had been in effect for over a year before we began data collection; therefore, to the extent that the effect of the policies change as shoppers become accustomed to them, a potentially more appropriate comparison of the two policies would focus on data collected roughly a year after the tax's implementation.

Figure 3a plots the proportion of customers using a disposable bag during the six data collection periods: the ban, the no regulation period, and the first four quarters of the tax separately for shoppers in Chicago and the surrounding unregulated suburbs. The figure shows that disposable bag use in the suburbs was relatively flat throughout the entire data collection period with a range of 87 to 92 percent of customers using at least one disposable bag per trip. In contrast, there was a large decrease in disposable bag use in Chicago in the first quarter of the tax. The difference in disposable bag use between Chicago and the suburbs, however, appears to decrease slightly starting in the third quarter. Figure 3b presents the same analysis for the average number of bags used per trip and exhibits a similar trajectory: disposable bag use was substantially lower in Chicago after the tax was implemented, but the number of disposable bags used appears to rebound somewhat over time.

Table 6 presents estimates from a regression that provides separate difference-in-difference estimates for the effect of the tax relative to the ban for each of the first four quarters of the tax's implementation. Specifically, the regression modifies the analysis in Panel B of Table 3 by including data from the follow-up period, adding separate main and interaction effects for each of the additional quarters.

Column 1 corresponds to Figure 3a, presenting results of the effects of the tax on the likelihood of using any disposable bags in a given trip. As in Table 3, we find that the tax led to a 33 
percentage point decrease in the proportion of customers using a disposable bag relative to the ban. This effect decreased slightly to a 31 percentage point change in the second quarter, though the difference between the two quarters is not statistically significant. However, by the end of the first year of the tax, we estimate that the tax led to a decrease in the proportion of customers using a disposable bag of 25 percentage points relative to the ban, an effect that is statistically significantly smaller than the effect measured in the first quarter of the tax's implementation.

This rebound effect is consistent with a model in which the salience of the tax decreases over time, potentially through a reduction in media coverage. Alternatively, prior literature suggests that the large observed behavioral response to disposable bag taxes may be due in part to loss aversion (Homonoff, 2018) - if a customer's reference price for a disposable bag is initially zero, a tax would feel like a loss. Our findings suggest that while customers may originally perceive a tax on disposable bags as a loss, their reference price may change over time as they acclimate to the tax, consistent with a model of expectations-based reference dependence (Kôszegi and Rabin, 2006). In other words, if customers come to expect that bags cost seven cents, the tax no longer feels like a loss and, as a result, the behavior change driven by their desire to avoid a loss fades.

Column 2 shows a similar pattern for the number of disposable bags used per trip: the tax led to a decrease of just under one disposable bag used per trip in the first quarter of the tax relative to the ban, but the effect is smaller and not statistically significant by the end of the first year. However, this estimate is somewhat misleading since customers who use thick plastic bags need to use fewer bags to carry the same amount of groceries. Columns 3 and 4 consider the effects of the tax on the amount of plastic used (measured in units of thin plastic bags as in Table 5) and the number of paper bags used, respectively. Here we find that the amount of plastic or paper used at the end of the first year of the tax was statistically significantly lower that the amount used during the ban. Additionally, we find no statistically significant differences in the amount of plastic or paper used during the first quarter of the tax compared to one year after the tax's implementation. 


\section{E. Robustness Checks}

\section{i. Bag Reuse}

One concern with the estimates in Table 5 is that customers may be more or less likely to reuse a disposable bag based on the type of bag. For example, Prendergast, Wai $\mathrm{Ng}$ and Lee Leung (2001) find that paper bags are reused almost twice as many times as plastic bags. If customers are more likely to reuse paper or thick plastic bags than thin plastic bags, the analysis in Table 5 will overstate the relative effectiveness of the tax in terms of environmental cost reduction. This also highlights a limitation of our data collection - while our researchers attempted to determine if a disposable bag was a new disposable bag, they could not always perfectly determine that the disposable bag had not been brought from home to be reused. ${ }^{27}$

Table 7 repeats the analyses in Table 5 allowing for reuse of paper and thick plastic bags. Specifically, we assume that thin plastic bags are used only once, while paper and thick plastic bags are used two times each (i.e., reused once). Even after this adjustment, we still observe significant differences in the amount of plastic and paper used under the two policies: customers use an equivalent of three fewer thin plastic bags and 0.5 fewer paper bags during the tax relative to the ban. Taken together, estimates in column 3 suggest that the tax led to a reduction in environmental costs equivalent to the use of 5 single-use thin plastic bags per shopping trip relative to the ban. Repeating the analysis in column 3 for additional reuses (see Appendix Table 1) shows that paper and thick plastic bags must be used a minimum of six times as often as thin plastic bags in order to no longer detect a significantly larger effect of the tax relative to the ban on overall environmental footprint - more than three times as often as suggested in Prendergast, Wai $\mathrm{Ng}$ and Lee Leung (2001). This suggests that our conclusions about the relative effectiveness of the two policies is robust to accounting for differences in reuse of different types of bags.

\footnotetext{
${ }^{27}$ Similarly, in our calculations in Table 5, we are only considering the environmental costs of disposable bags and not reusable bags. However, Edwards and Fry (2011) estimate that standard reusable bags must be reused more than 10 times in order to generate lower environmental costs than a single-use plastic bag. By ignoring the costs of reusable bags, our calculations implicitly assume that reusable bags are reused a sufficient number of times such that their costs (relative to those of disposable bags) are negligible.
} 


\section{ii. Spillover Effects}

One of the key benefits of our setting is that we are able to compare two policy designs within the same city using stores in the same county, which are subject to the same state and county level regulations and which may draw similar customers, as a control. Conversely, a concern with this study design is that there may be spillover effects if policies in Chicago have an effect on the behavior of customers or retailers in neighboring cities. For example, if a customer shops at both Chicago and suburban stores, they may respond to the tax by switching to reusable bags in both stores, thereby biasing our estimate of the policy. Importantly, in this example, this would, if anything, attenuate the magnitude of the effect we estimate toward zero. However, if instead the policy leads customers who prefer disposable bags to shift their shopping to suburban stores instead of Chicago stores, this bias could potentially drive our results.

Table 8 tests the sensitivity of our results to spillover effects by replicating our main results excluding the four stores in our sample located in ZIP codes that border the Chicago city line. We find that our results are qualitatively unchanged as a result of this restriction. While we cannot completely rule out the possibility of spillover effects with our data, these finding suggest that our results are unlikely to be driven by this bias.

\section{Conclusion}

This paper evaluates the relative effectiveness of two policies in Chicago aimed at reducing the use of disposable shopping bags: a ban on thin plastic bags and a tax on all disposable bags. We do so by comparing changes in disposable bag use in response to the repeal of a plastic bag ban and the subsequent introduction of a disposable bag tax in the city of Chicago. We find that the ban repeal had no effect on the proportion of customers using a disposable bag, while the implementation of the tax led to a large decrease. Additionally, the ban led to the introduction of free thick plastic bags, a product that was eliminated after the ban was repealed. This suggests that all disposable bag regulations do not appear to be equally effective: the tax was significantly more successful than the ban at reducing the proportion of customers using a disposable bag as well as the amount of paper and plastic used.

It is worth noting several key data limitations to estimating the overall environmental benefits 
(or costs) of the policies. First, we do not have data on purchases of plastic trash bags which may offset the decreases in overall plastic used (Taylor, 2019). Second, we do not have data on reuse of different types of bags. For example, if customers reuse thick plastic bags many more times than thin plastic bags (by our estimates, roughly 20 times as many), then a switch from thin to thick bags could actually reduce environmental costs (Edwards and Fry, 2011). Similarly, we do not calculate environmental costs associated with reusable bags; therefore, if the tax increases purchases of reusable bags (rather than use of existing reusable bags), our estimates would overstate the environmental benefits of the tax. ${ }^{28}$ Finally, our data was collected during weekdays only; to the extent that customers shopping on the weekends respond differently to the policies, we may misrepresent the overall effect of the policies on bag use.

Additionally, our paper focuses only on the relative effect of these policies on environmental costs. A full welfare analysis is beyond the scope of this paper, however, it is worth highlighting a few factors that contribute to potential differences across the two policies. First, a plastic bag ban creates a larger direct financial cost for retailers in the form of providing higher cost bags (paper or thicker plastic) ${ }^{29}$ while the tax creates a direct cost for consumers; however, it is necessary to determine the incidence of those respective costs in order to assess the welfare implications. Second, the two policies have different revenue implications for the government: the tax raised an average of $\$ 6$ million dollars in each of the first two years (Giangreco, 2019), while the ban generates no revenue at all. Finally, there may be other potential unintended consequences associated with the disposable bag regulations, such as increases in checkout wait times (Taylor, 2020b) or losses in sales (Cabrera, Caffera and Cid, 2020; Taylor, 2020a).

Nonetheless, given the rapid expansion of regulations restricting the use of disposable bags, our results have important implications for policymakers considering regulations of different designs. One potential implication of our findings is that increasing the thickness of plastic bags regulated by plastic bag bans may discourage retailers from providing alternative free plastic bags. However, this policy change may simply lead to a larger shift toward disposable paper bags which have their own environmental costs. Our findings also have implications for policymakers choosing between

\footnotetext{
${ }^{28}$ Edwards and Fry (2011) estimates that non-woven polypropylene reusable bags must be reused at least 11 times more than a thin plastic bag in order to have a smaller environmental footprint.

${ }^{29}$ For example, a thin plastic grocery bag costs about one cent to produce while a paper bag costs between 4 and 5 cents (Conway, 2007).
} 
market-based policies and stand-alone bans. For example, Connecticut is transitioning from a 10cent disposable bag fee to a plastic bag ban in 2021. Similarly, New York City passed a five-cent fee on all disposable bags in 2016 which was overturned and replaced with a statewide policy banning the use of thin plastic bags in 2020. The New York State policy gives individual counties the option of implementing a five-cent fee on paper bags - our results suggest that the success of the New York policy rests heavily on the choice that the individual counties make. 


\section{References}

ACS. 2017. "American Community Survey 5-Year Estimates."

Adda, Jérôme, and Francesca Cornaglia. 2010. "The effect of bans and taxes on passive smoking." American Economic Journal: Applied Economics, 2(1): 1-32.

Allcott, Hunt, Benjamin B. Lockwood, and Dmitry Taubinsky. 2019. "Should We Tax Sugar-Sweetened Beverages? An Overview of Theory and Evidence." Journal of Economic Perspectives, 33(3): 202-27.

Bharadwaj, Bishal, Jean Marie Baland, and Mani Nepal. 2020. "What makes a ban on plastic bags effective? The case of Nepal." Environment and Development Economics, 25(2): 95114.

Bhutta, Neil, Jacob Goldin, and Tatiana Homonoff. 2016. "Consumer borrowing after payday loan bans." The Journal of Law and Economics, 59(1): 225-259.

Brescoll, Victoria L., Rogan Kersh, and Kelly D. Brownell. 2008. "Assessing the Feasibility and Impact of Federal Childhood Obesity Policies." The Annals of the American Academy of Political and Social Science, 615(1): 178-194.

Britschgi, Christian. 2018. "Media, Legislators, Activists Stick By Straw Stats Produced By 9-Year-Old."

Cabrera, José María, Marcelo Caffera, and Alejandro Cid. 2020. "Modest and Incomplete Incentives May Have Very Large Effects: The Impact of Prices on the Demand for Plastic Bags." Mimeo.

Cameron, A Colin, Jonah B Gelbach, and Douglas L Miller. 2008. "Bootstrap-Based Improvements for Inference with Clustered Errors." The Review of Economics and Statistics, 90(3): 414-427.

Cawley, John, Anne Marie Thow, Katherine Wen, and David Frisvold. 2019. "The economics of taxes on sugar-sweetened beverages: a review of the effects on prices, sales, cross-border shopping, and consumption." Annual review of nutrition, 39: 317-338. 
Clapp, Jennifer, and Linda Swanston. 2009. "Doing Away with Plastic Shopping Bags: International Patterns of Norm Emergence and Policy Implementation." Environmental Politics, 18(3): 315-332.

Conway, Chris. 2007. "Taking Aim at All Those Plastic Bags." New York Times.

Davis, Lucas W. 2008. "The effect of driving restrictions on air quality in Mexico City." Journal of Political Economy, 116(1): 38-81.

Edwards, Chris, and Jonna Meyhoff Fry. 2011. "Life cycle assessment of supermarket carrier bags." Environment Agency, Horizon House, Deanery Road, Bristol, BS1 5AH.

Fowlie, Meredith L. 2009. "Incomplete Environmental Regulation, Imperfect Competition, and Emissions Leakage." American Economic Journal: Economic Policy, 1(2): 72-112.

Gardinier, Dustin. 2019. "California Banned Plastic Bags. So Why Do Stores Keep Using Them?" San Francisco Chronicle.

Giangreco, Leigh. 2019. "How Behavioral Science Solved Chicago's Plastic Bag Problem." Politico.

Grynbaum, Michael M. 2014. "New Yorks Ban on Big Sodas Is Rejected by Final Court." New York Times.

Gupta, Kanupriya. 2011. Consumer responses to incentives to reduce plastic bag use: Evidence from a field experiment in urban India. SAMDEE.

Homonoff, Tatiana A. 2018. "Can small incentives have large effects? The impact of taxes versus bonuses on disposable bag use." American Economic Journal: Economic Policy, 10(4): 177-210.

Jakovcevic, Adriana, Linda Steg, Nadia Mazzeo, Romina Caballero, Paul Franco, Natalia Putrino, and Jesica Favara. 2014. "Charges for plastic bags: Motivational and behavioral effects." Journal of Environmental Psychology, 40: 372-380.

Kôszegi, Botond, and Matthew Rabin. 2006. "A Model of Reference-Dependent Preferences." The Quarterly Journal of Economics, 121(4): 1133-1165.

Lichtman-Sadot, Shirlee. 2016. "Does banning carbonated beverages in schools decrease student consumption?" Journal of Public Economics, 140: 30-50. 
Malani, Anup, and Julian Reif. 2015. "Interpreting pre-trends as anticipation: Impact on estimated treatment effects from tort reform." Journal of Public Economics, 124: 1-17.

Nielsen, Tobias Dan, Karl Holmberg, and Johannes Stripple. 2019. "Need a bag? A review of public policies on plastic carrier bags-Where, how and to what effect?" Waste management, 87: $428-440$.

Pervin, Ismat Ara, Sheikh Mohammad Mahbubur Rahman, Mani Nepal, Abdul Kalam Enamul Haque, Humayun Karim, and Ganesh Dhakal. 2020. "Adapting to urban flooding: a case of two cities in South Asia." Water Policy, 22(S1): 162-188.

Poortinga, Wouter, Lorraine Whitmarsh, and Christine Suffolk. 2013. "The introduction of a single-use carrier bag charge in Wales: Attitude change and behavioural spillover effects." Journal of Environmental Psychology, 36: 240-247.

Prendergast, Gerard, Shuk Wai Ng, and Lee Lee Leung. 2001. "Consumer perceptions of shopping bags." Marketing Intelligence Ef Planning, 19(7): 475-482.

Rivers, Nicholas, Sarah Shenstone-Harris, and Nathan Young. 2017. "Using nudges to reduce waste? The case of Toronto's plastic bag levy." Journal of environmental management, 188: $153-162$.

Rochman, Bonnie. 2018. "Straws are out, lids are in: Starbucks announces environmental milestone."

Romer, Jennie R, and Leslie Mintz Tamminen. 2014. "Plastic bag reduction ordinances: New York city's proposed charge on all carryout bags as a model for US cities." Tulane Environmental Law Journal, 27(2): 237-275.

Solomon, Molly. 2016. "One Year After The Ban, Plastic Bags Still An Issue On Oahu."

Taylor, Rebecca. 2020a. "Its in the Bag? The Effect of Plastic Carryout Bag Bans on Where and What People Purchase to Eat." Mimeo.

Taylor, Rebecca L, and Sofia B Villas-Boas. 2016. "Bans vs. Fees: Disposable Carryout Bag Policies and Bag Usage." Applied Economic Perspectives and Policy, 38(2): 351-372. 
Taylor, Rebecca LC. 2019. "Bag leakage: The effect of disposable carryout bag regulations on unregulated bags." Journal of Environmental Economics and Management, 93: 254-271.

Taylor, Rebecca LC. 2020b. "A Mixed Bag: The Hidden Time Costs of Regulating Consumer Behavior." Journal of the Association of Environmental and Resource Economists, 7(2): 345-378.

USEPA, United States Environmental Protection Agency. 2018. "Municipal Solid Waste in the United States: Facts and Figures."

Wagner, Travis P. 2017. "Reducing single-use plastic shopping bags in the USA." Waste Management, 70: 3-12.

White, Jeremy. 2019. "When Lawmakers Try to Ban Assault Weapons, Gunmakers Adapt." New York Times.

Wilson, Brent M, Stephanie Stolarz-Fantino, and Edmund Fantino. 2013. "Regulating the way to obesity: unintended consequences of limiting sugary drink sizes." PloS one, 8(4): e61081. 
Figure 1: Map of ZIP Codes Included in Sample

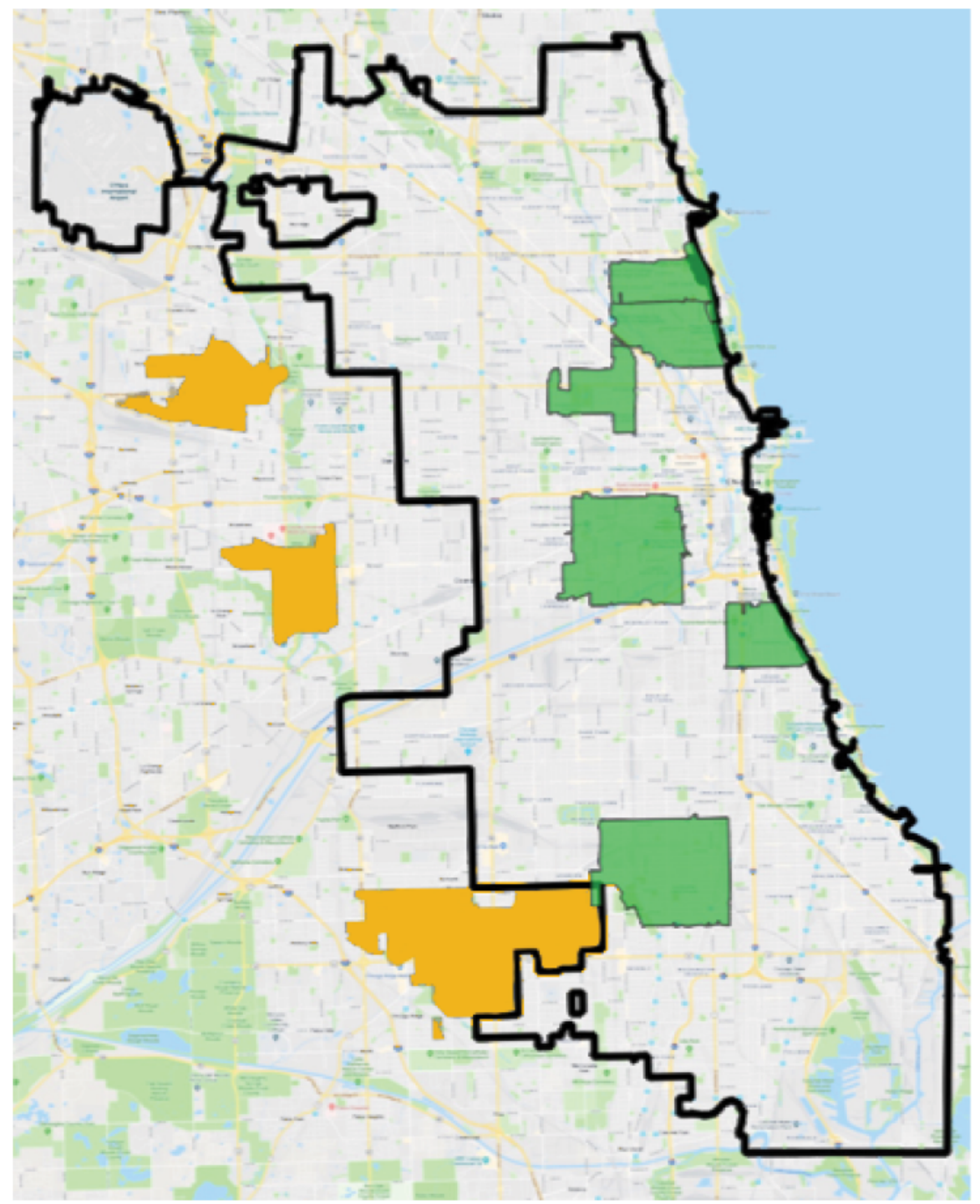

Green areas represent the ZIP codes of Chicago stores included in our study sample. Orange areas represent the ZIP codes of suburban stores included in our study sample. The black boundary is the border of the city of Chicago. 
Figure 2: Disposable Bag Use by Bag Type

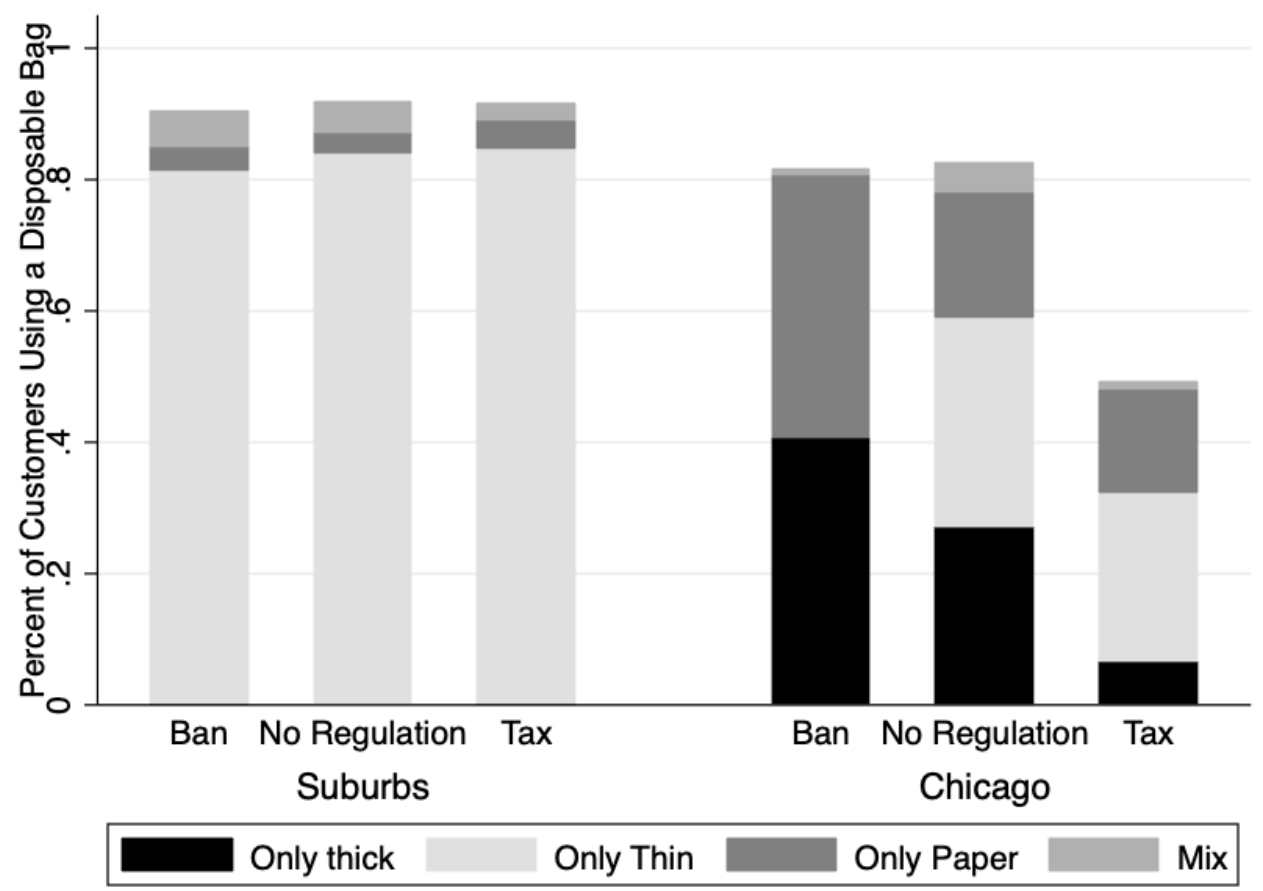

The height of each bar represents the proportion of customers using a disposable bag separately for Chicago and the surrounding suburbs during the three main study periods: the Chicago plastic bag ban (November-December 2016), the one month of no regulation following the ban's repeal (January 2017), and the first months of the Chicago disposable bag tax (February-March 2017). Shading represents the proportion of customers who used only thick plastic bags, only thin plastic bags, only paper bags, or a mix of disposable bag types. 
Figure 3: Disposable Bag Use Over Time

(a) Proportion of Customers Using a Disposable Bag

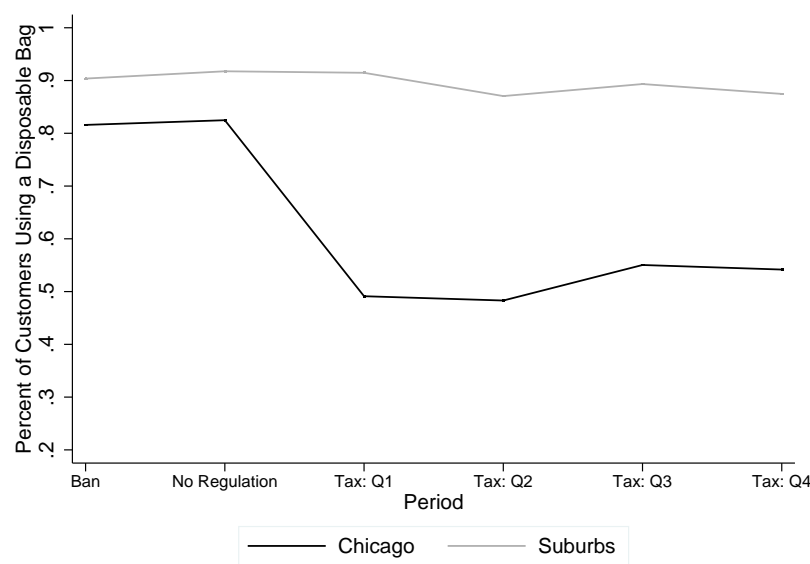

(b) Average Number of Disposable Bags Used per Trip

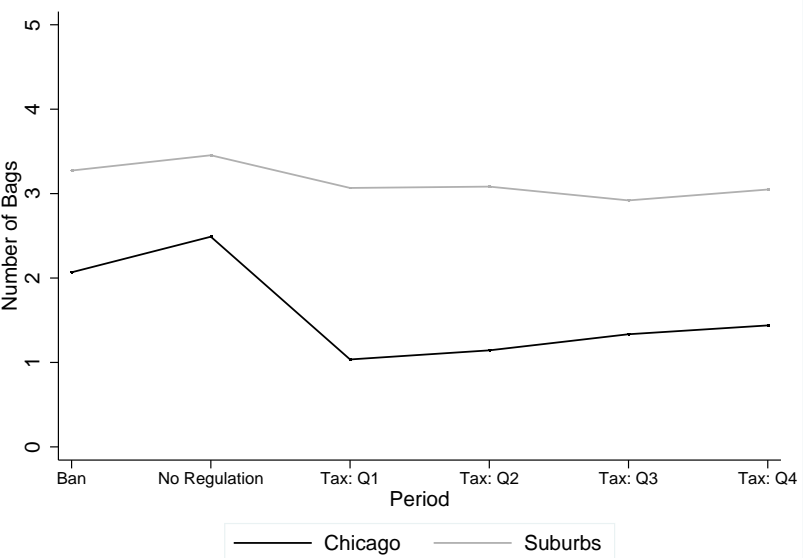

Figure reports the proportion of customers using a disposable bag (Panel A) and the average number of disposable bags used per trip (Panel B) separately for Chicago and the surrounding suburbs during the six study periods: the Chicago plastic bag ban (November-December 2016), the one month of no regulation following the ban's repeal (January 2017), and the first four quarters of the Chicago disposable bag tax (February 2017 - March 2018). 
Table 1: Sample Store Characteristics

\begin{tabular}{lccccc}
\hline Store & Observations & Chicago & \% White & \% Male & Median ZIP Income \\
\hline 1 & 2,005 & & 43.4 & 42.7 & 45,548 \\
2 & 1,801 & & 46.9 & 39.7 & 70,270 \\
3 & 2,190 & & 30.1 & 36.0 & 65,744 \\
4 & 2,401 & & 68.7 & 40.1 & 57,410 \\
5 & 1,646 & x & 1.3 & 40.9 & 32,557 \\
6 & 2,039 & x & 74.8 & 44.3 & 78,796 \\
7 & 2,101 & x & 80.1 & 45.9 & 88,256 \\
8 & 1,910 & x & 7.6 & 36.9 & 25,343 \\
9 & 2,095 & x & 62.4 & 50.5 & 71,019 \\
10 & 2,185 & x & 72.5 & 49.1 & 71,019 \\
11 & 1,971 & x & 1.0 & 39.5 & 32,557 \\
12 & 1,658 & x & 7.7 & 40.2 & 35,112 \\
\hline
\end{tabular}

Table reports the number of observations per store, store location, the fraction of sample members who were white and male, respectively, and the median household income in the store's ZIP code. Each observation refers to one shopping trip. Sample sizes reported include observations from the full study period (November 2016-March 2018).

Table 2: Bag Use by Location and Policy

\begin{tabular}{lccc|ccc}
\hline & Ban & $\begin{array}{c}\text { Suburbs } \\
\text { No Regulation }\end{array}$ & $\begin{array}{c}\text { Tax } \\
(3)\end{array}$ & $\begin{array}{c}\text { Chicago } \\
(4)\end{array}$ & $\begin{array}{c}\text { No Regulation } \\
(5)\end{array}$ & $\begin{array}{c}\text { Tax } \\
(6)\end{array}$ \\
\hline Any Disposable Bag & 0.90 & 0.92 & 0.91 & 0.82 & 0.82 & 0.49 \\
& $(0.30)$ & $(0.28)$ & $(0.28)$ & $(0.39)$ & $(0.38)$ & $(0.50)$ \\
Any Reusable Bag & 0.08 & 0.04 & 0.06 & 0.13 & 0.14 & 0.33 \\
& $(0.27)$ & $(0.19)$ & $(0.24)$ & $(0.33)$ & $(0.34)$ & $(0.47)$ \\
No Bags & 0.05 & 0.05 & 0.04 & 0.09 & 0.07 & 0.21 \\
& $(0.21)$ & $(0.22)$ & $(0.20)$ & $(0.28)$ & $(0.26)$ & $(0.41)$ \\
\# Total Bags & 3.39 & 3.53 & 3.20 & 2.28 & 2.72 & 1.64 \\
& $(2.99)$ & $(2.96)$ & $(2.66)$ & $(2.03)$ & $(2.58)$ & $(1.70)$ \\
\# Disposable Bags & 3.27 & 3.45 & 3.07 & 2.07 & 2.49 & 1.04 \\
& $(3.02)$ & $(3.00)$ & $(2.70)$ & $(2.10)$ & $(2.66)$ & $(1.60)$ \\
\hline \hline Observations & 1,454 & 1,370 & 1,406 & 2,694 & 2,568 & 2,724
\end{tabular}

Table reports the fraction of customers using any disposable bags, any reusable bags, and no bags at all along with the average number of disposable bags used per trip separately for customers shopping in Chicago and the surrounding suburbs under different policy regimes. The "Ban" period refers to the final months of the Chicago plastic bag ban (November-December 2016), "Tax" refers to the first two months of the Chicago disposable bag tax (February-March 2017), and "No Regulation" refers to the one-month period after the repeal of the ban and before the implementation of the tax (January 2017). Standard deviations in parentheses. 
Table 3: Effect of Disposable Bag Regulation on Bag Use

\begin{tabular}{lcccc}
\hline \multicolumn{2}{c}{$\begin{array}{c}\text { Any Disposable Bag } \\
(1)\end{array}$} & $\begin{array}{c}\text { Disposable Bags } \\
(2)\end{array}$ & $\begin{array}{c}\text { Any Reusable Bag } \\
(3)\end{array}$ & $\begin{array}{c}\text { No Bag } \\
(4)\end{array}$ \\
\hline A. Effect of Ban and Tax vs. No Regulation & & & \\
\hline ChicagoxBan & -0.004 & -0.232 & -0.037 & 0.024 \\
Ban & $(0.033)$ & $(0.165)$ & $(0.028)$ & $(0.018)$ \\
& -0.005 & -0.166 & 0.027 & -0.006 \\
ChicagoxTax & $(0.030)$ & $(0.113)$ & $(0.028)$ & $(0.013)$ \\
& $-0.332^{* * *}$ & $-1.087^{* * *}$ & $0.168^{* * *}$ & $0.160^{* * *}$ \\
Tax & $(0.030)$ & $(0.270)$ & $(0.022)$ & $(0.028)$ \\
& -0.000 & $-0.348^{* * *}$ & $0.022^{* * *}$ & -0.014 \\
\hline Observations & $(0.013)$ & $(0.109)$ & $(0.006)$ & $(0.009)$ \\
\hline B. Relative Effect of Tax vs. Ban & 12,216 & 12,216 & 12,216 \\
\hline ChicagoxTax & 12,216 & & & \\
& $\left(0.330^{* * *}\right.$ & $-0.860^{* * *}$ & $0.204^{* * *}$ & $0.138^{* * *}$ \\
Tax & $(0.037)$ & $(0.221)$ & $(0.033)$ & $(0.020)$ \\
& 0.006 & -0.172 & -0.004 & -0.010 \\
\hline \hline Observations & $(0.021)$ & $(0.168)$ & $(0.022)$ & $(0.007)$ \\
Dep Var Mean & 8,278 & 8,278 & 8,278 & 8,278 \\
& 0.918 & 3.454 & 0.039 & 0.053
\end{tabular}

Standard errors clustered at the store level in parentheses. Outcome variables are indicators for whether a customer used any disposable bags (column 1), the number of disposable bags used per trip (column 2), whether the customer used any reusable bags (column 3), and if the customer used no bags at all (column 4). "Chicago" is an indicator for shopping in Chicago (versus the surrounding suburbs), "Ban" is an indicator for shopping during the Chicago plastic bag ban (versus during the period with no disposable bag regulation), and "Tax" is an indicator for shopping during the Chicago disposable bag tax (versus during the period with no disposable bag regulation). Panel A includes customers shopping in either the ban, the no regulation, or the tax period (reference group = no regulation); Panel B includes only customers shopping in either the tax or the ban period (reference group $=$ ban). All regressions control for customer sex and race as well as store, time of day, and data collector fixed effects. Dependent variable mean evaluated for customers in the suburbs during the no regulation period. ${ }^{*} \mathrm{p}<.05 ;{ }^{* *} \mathrm{p}<.01 ;{ }^{* * *} \mathrm{p}<.001$. 
Table 4: Effect of Disposable Bag Tax vs. Plastic Bag Ban on Disposable Bag Use

\begin{tabular}{lcccc}
\hline & Only Thick & Only Thin & Only Paper & Mix Disposable \\
& $(1)$ & $(2)$ & $(3)$ & $(4)$ \\
\hline ChicagoxTax (vs. Ban) & $-0.325^{* *}$ & $0.234^{* * *}$ & $-0.267^{* *}$ & $0.029^{* *}$ \\
& $(0.115)$ & $(0.046)$ & $(0.099)$ & $(0.012)$ \\
Tax & 0.003 & 0.024 & 0.006 & $-0.027^{* *}$ \\
& $(0.018)$ & $(0.030)$ & $(0.012)$ & $(0.011)$ \\
\hline \hline Observations & 8,278 & 8,278 & 8,278 & 8,278 \\
Dep Var Mean & 0.001 & 0.813 & 0.036 & 0.054
\end{tabular}

Standard errors clustered at the store level in parentheses. Outcome variables are indicators for using only thick plastic bags (column 1), only thin plastic bags (column 2), only paper bags (column 3), or using a mix of disposable bag types (column 4). "Chicago" is an indicator for shopping in Chicago (versus the surrounding suburbs) and "Tax" is an indicator for shopping during the Chicago disposable bag tax (versus during the the Chicago plastic bag ban). Analyses exclude the one month period of no disposable bag regulation between the plastic bag ban and the disposable bag tax. All regressions control for customer sex and race as well as store, time of day, and data collector fixed effects. Dependent variable mean evaluated for customers in the suburbs during the Chicago bag ban. ${ }^{*} \mathrm{p}<.05$; $* * \mathrm{p}<.01 ; * * * \mathrm{p}<.001$.

Table 5: Effect of Disposable Bag Tax vs. Plastic Bag Ban on Environmental Costs

\begin{tabular}{lccc}
\hline & $\begin{array}{c}\text { Amount Plastic } \\
(1)\end{array}$ & $\begin{array}{c}\text { Amount Paper } \\
(2)\end{array}$ & $\begin{array}{c}\text { Environmental Footprint } \\
(3)\end{array}$ \\
\hline ChicagoxTax (vs. Ban) & $-3.771^{* *}$ & $-0.684^{*}$ & $-6.473^{* * *}$ \\
& $(1.523)$ & $(0.339)$ & $(0.886)$ \\
Tax & -0.118 & -0.011 & -0.260 \\
& $(0.126)$ & $(0.050)$ & $(0.237)$ \\
\hline \hline Observations & 8,278 & 8,278 & 8,278 \\
Dep Var Mean & 3.093 & 0.186 & 4.018
\end{tabular}

Standard errors clustered at the store level in parentheses. Outcome variables are indicators for total plastic used per shopping trip where the units are in numbers of thin plastic bags (column 1), total paper used per shopping trip where the units are in numbers of paper bags (column 2) and the environmental cost generated from the use of both plastic and paper bags measured in units of cost generated from one thin plastic bag (column 3). Calculations assume that environmental costs of paper bags and thick plastic bags are four and five times that of thin plastic bags, respectively, and that all disposable bags are reused the same number of times. "Chicago" is an indicator for shopping in Chicago (versus the surrounding suburbs) and "Tax" is an indicator for shopping during the Chicago disposable bag tax (versus during the the Chicago plastic bag ban). Analyses exclude the one month period of no disposable bag regulation between the plastic bag ban and the disposable bag tax. All regressions control for customer sex and race as well as store, time of day, and data collector fixed effects. Dependent variable mean evaluated for customers in the suburbs during the Chicago bag ban. ${ }^{*} \mathrm{p}<.05 ;{ }^{*} \mathrm{p}<.01 ; * * * \mathrm{p}<.001$. 
Table 6: Effect of Disposable Bag Tax vs. Plastic Bag Ban by Quarter of Implementation

\begin{tabular}{|c|c|c|c|c|}
\hline & $\begin{array}{c}\text { Any Disposable Bag } \\
(1)\end{array}$ & $\begin{array}{l}\text { \# Disposable Bags } \\
(2)\end{array}$ & $\begin{array}{c}\text { Amount of Plastic } \\
(3)\end{array}$ & $\begin{array}{l}\text { Amount of Paper } \\
\text { (4) }\end{array}$ \\
\hline \multirow[t]{2}{*}{ Chicago x Tax Q1 } & $-0.330 * * *$ & $-0.879^{* * *}$ & $-3.886^{* *}$ & $-0.680^{*}$ \\
\hline & $(0.036)$ & $(0.236)$ & $(1.512)$ & $(0.329)$ \\
\hline \multirow[t]{2}{*}{ Chicago x Tax Q2 } & $-0.314^{* * *}$ & $-0.559 * *$ & $-4.117^{* *}$ & $-0.617^{* *}$ \\
\hline & $(0.034)$ & $(0.186)$ & $(1.779)$ & $(0.277)$ \\
\hline \multirow[t]{2}{*}{ Chicago x Tax Q3 } & $-0.252^{* * *}$ & -0.227 & $-4.041^{* *}$ & -0.469 \\
\hline & $(0.033)$ & $(0.347)$ & $(1.676)$ & $(0.276)$ \\
\hline \multirow[t]{2}{*}{ Chicago x Tax Q4 } & $-0.248^{* * *}$ & -0.319 & $-3.970^{* *}$ & $-0.495^{*}$ \\
\hline & $(0.028)$ & $(0.244)$ & $(1.634)$ & $(0.248)$ \\
\hline \multirow[t]{2}{*}{ Tax: Q1 } & 0.007 & -0.159 & -0.142 & -0.004 \\
\hline & $(0.020)$ & $(0.187)$ & $(0.138)$ & $(0.052)$ \\
\hline \multirow[t]{2}{*}{ Tax: Q2 } & -0.021 & $-0.471^{* * *}$ & -0.370 & -0.117 \\
\hline & $(0.028)$ & $(0.118)$ & $(0.485)$ & $(0.160)$ \\
\hline \multirow[t]{2}{*}{ Tax: Q3 } & -0.023 & -0.502 & -0.171 & 0.033 \\
\hline & $(0.024)$ & $(0.399)$ & $(0.722)$ & $(0.124)$ \\
\hline \multirow[t]{2}{*}{ Tax: Q4 } & -0.026 & -0.195 & 0.137 & 0.092 \\
\hline & $(0.026)$ & $(0.302)$ & $(0.763)$ & $(0.119)$ \\
\hline Observations & 20,064 & 20,064 & 20,064 & 20,064 \\
\hline Dep Var Mean & 0.904 & 3.273 & 3.093 & 0.186 \\
\hline
\end{tabular}

Standard errors clustered at the store level in parentheses. Outcome variables are indicators for whether a customer used any disposable bag (column 1), the number of disposable bags used per trip (column 2), total plastic used per shopping trip where the units are in numbers of thin plastic bags (column 3) and total paper used per shopping trip where the units are in numbers of paper bags (column 4). "Chicago" is an indicator for shopping in Chicago (versus the surrounding suburbs). "Tax: Q1" through "Tax: Q4" are indicators for shopping during each of the first four quarters of the Chicago disposable bag tax, respectively, with an omitted category of the period during the Chicago plastic bag ban. Analyses exclude the one month period of no disposable bag regulation between the plastic bag ban and the disposable bag tax. All regressions control for customer sex and race as well as store, time of day, and data collector fixed effects. Dependent variable mean evaluated for customers in the suburbs during the Chicago bag ban. ${ }^{*} \mathrm{p}<.05 ;{ }^{* *} \mathrm{p}<.01 ;{ }^{* * *} \mathrm{p}<.001$. 
Table 7: Effect of Disposable Bag Tax vs. Plastic Bag Ban on Environmental Costs - Robustness to Bag Reuse

\begin{tabular}{lccc}
\hline & $\begin{array}{c}\text { Amount Plastic } \\
(1)\end{array}$ & $\begin{array}{c}\text { Amount Paper } \\
(2)\end{array}$ & $\begin{array}{c}\text { Environmental Footprint } \\
(3)\end{array}$ \\
\hline ChicagoxTax (vs. Ban) & $-2.872^{* *}$ & $-0.513^{*}$ & $-4.873^{* * *}$ \\
& $(1.209)$ & $(0.254)$ & $(0.694)$ \\
Tax & -0.129 & -0.009 & -0.263 \\
& $(0.105)$ & $(0.037)$ & $(0.204)$ \\
\hline \hline Observations & 8,278 & 8,278 & 8,278 \\
Dep Var Mean & 4.018 & 0.139 & 3.831
\end{tabular}

Standard errors clustered at the store level in parentheses. Outcome variables are indicators for total plastic used per shopping trip where the units are in numbers of thin plastic bags (column 1), total paper used per shopping trip where the units are in numbers of paper bags (column 2) and the environmental cost generated from the use of both plastic and paper bags measured in units of cost generated from one thin plastic bag (column 3). Calculations assume that environmental costs of paper bags and thick plastic bags are four and five times that of thin plastic bags, respectively, and that thin plastic bags are used only once, while paper and thick plastic bags are used two times each (i.e. reused once). "Chicago" is an indicator for shopping in Chicago (versus the surrounding suburbs) and "Tax" is an indicator for shopping during the Chicago disposable bag tax (versus during the the Chicago plastic bag ban). Analyses exclude the one month period of no disposable bag regulation between the plastic bag ban and the disposable bag tax. All regressions control for customer sex and race as well as store, time of day, and data collector fixed effects. Dependent variable mean evaluated for customers in the suburbs during the Chicago bag ban. ${ }^{*} \mathrm{p}<.05$; $* * \mathrm{p}<.01 ; * * * \mathrm{p}<.001$.

Table 8: Effect of Disposable Bag Tax vs. Plastic Bag Ban - Robustness to Spillover Effects

\begin{tabular}{lcccc}
\hline & Any Disposable Bag & \# Disposable Bags & Any Reusable Bag & No Bag \\
& $(1)$ & $(2)$ & $(3)$ & $(4)$ \\
\hline ChicagoxTax (vs. Ban) & $-0.305^{* * *}$ & $-1.069^{* *}$ & $0.173^{* * *}$ & $0.127^{* * *}$ \\
& $(0.035)$ & $(0.337)$ & $(0.025)$ & $(0.025)$ \\
Tax & -0.008 & 0.099 & $0.034^{* * *}$ & -0.022 \\
& $(0.011)$ & $(0.275)$ & $(0.007)$ & $(0.013)$ \\
\hline \hline Observations & 5,459 & 5,459 & 5,459 & 5,459 \\
Dep Var Mean & 0.914 & 2.643 & 0.038 & 0.061
\end{tabular}

Standard errors clustered at the store level in parentheses. Outcome variables are indicators for whether a customer used any disposable bags (column 1), the number of disposable bags used per trip (column 2), whether the customer used any reusable bags (column 3), and if the customer used no bags at all (column 4). "Chicago" is an indicator for shopping in Chicago (versus the surrounding suburbs) and "Tax" is an indicator for shopping during the Chicago disposable bag tax (versus during the the Chicago plastic bag ban). Analyses exclude the one month period of no disposable bag regulation between the plastic bag ban and the disposable bag tax and stores located in ZIP codes that border the Chicago city line. All regressions control for customer sex and race as well as store, time of day, and data collector fixed effects. Dependent variable mean evaluated for customers in the suburbs during the Chicago bag ban. ${ }^{*} \mathrm{p}<.05 ;{ }^{* *} \mathrm{p}<.01 ;{ }^{* * *} \mathrm{p}<.001$. 
Appendix Table 1: Effect on Environmental Footprint by Reuse

\begin{tabular}{lccccc}
\hline & 1 Reuse & 2 Reuses & 3 Reuses & 4 Reuses & 5 Reuses \\
& $(1)$ & $(2)$ & $(3)$ & $(4)$ & $(5)$ \\
\hline ChicagoxTax (vs. Ban) & $-4.873^{* * *}$ & $-3.273^{* * *}$ & $-1.672^{* * *}$ & $-0.627^{* *}$ & -0.383 \\
& $(0.694)$ & $(0.518)$ & $(0.380)$ & $(0.237)$ & $(0.229)$ \\
Tax & -0.263 & -0.266 & -0.268 & -0.278 & -0.278 \\
& $(0.204)$ & $(0.183)$ & $(0.179)$ & $(0.208)$ & $(0.211)$ \\
\hline \hline Observations & 8,278 & 8,278 & 8,278 & 8,278 & 8,278 \\
Dep Var Mean & 3.831 & 3.644 & 3.457 & 3.418 & 3.393
\end{tabular}

Standard errors clustered at the store level in parentheses. The outcome variable in all columns is the environmental cost generated from the use of one single-use plastic bag. Calculations assume that the environmental costs of paper bags and thick plastic bags are four and five times that of thin plastic bags, respectively. Each column makes a different assumption about the number of reuses of paper and thick plastic bags relative to thin plastic bags: columns 1 through 5 assume that thin plastic bags are used only once but paper and thick plastic bags are reused one to five times, respectively. "Chicago" is an indicator for shopping in Chicago (versus the surrounding suburbs) and "Tax" is an indicator for shopping during the Chicago disposable bag tax (versus during the the Chicago plastic bag ban). Analyses exclude the one month period of no disposable bag regulation between the plastic bag ban and the disposable bag tax. All regressions control for customer sex and race as well as store, time of day, and data collector fixed effects. Dependent variable mean evaluated for customers in the suburbs during the Chicago bag ban. ${ }^{*} \mathrm{p}<.05 ;{ }^{* *} \mathrm{p}<.01 ;{ }^{* *} \mathrm{p}<.001$. 